\title{
Bidirectional shunt in uncomplicated atrial septal defect
}

\author{
ENRIQUE GALVE, JUAN ANGEL, ARTURO EVANGELISTA, INOCENCIO ANIVARRO, \\ G PERMANYER-MIRALDA, J SOLER-SOLER
}

From the Cardiology Service, Department of Medicine, Ciudad Sanitaria, Valle Hebrón, Barcelona, Spain

SUMMARY The presence of right to left shunts at atrial level in $\mathbf{4 0}$ patients with an uncomplicated atrial septal defect was determined by measuring the pulmonary vein to systemic artery oxygen stepdown. In six patients (group 1) a sizeable right to left shunt was found: left atrial oxygen stepdown was $\geqslant 0.7 \mathrm{vol} \%$, mean right to left shunt $0.671 / \mathrm{min} / \mathrm{m}^{2}$ (range $0.36-1.0$ ), and arterial oxygen saturation between $84 \%$ and $90.5 \%$. The patients in group 1 did not show any differences from those with left to right shunts alone (group 2) as regards sex, cardiac rhythm, heart rate, "a" wave and mean right atrial pressure, end diastolic right ventricular pressure, morphology of diastolic right ventricular pressure curves, pulmonary to systemic vascular resistance ratio, size of the defect, and coexistence of anomalous pulmonary venous drainage. Patients with coexisting right to left shunts were, however, significantly older and had smaller left to right shunts.

Thus an appreciable number of patients with uncomplicated atrial septal defects have major right to left shunts which are unrelated to pulmonary hypertension or right heart failure. These shunts may be detected by the usual oximetric techniques and apparently develop with age, which suggests that they result from changes associated with chronic right volume overload.

In an uncomplicated atrial septal defect the direction of interatrial flow is from right to left at birth; thereafter, the fall in pulmonary vascular resistance during the neonatal period results in a left to right shunt. This pattern of flow can be reversed again during the natural history of an atrial septal defect if pulmonary vascular hypertension develops. In the absence of right heart failure or pulmonary hypertension, however, an atrial septal defect may cause a minor right to left shunt associated with the dominant left to right shunt, which is detectable only by complex techniques $^{1-3}$; in these cases confirmation by determining oxygen saturation values is impossible. There are isolated reports of atrial septal defect associated with systemic arterial desaturation and cyanosis poorly explained by the haemodynamic data. ${ }^{4-8}$ In addition, in some patients the right to left shunt has been discovered indirectly by measuring only systemic arterial oxygen tension. ${ }^{110}$

Requests for reprints to Dr Enrique Galve, Servicio de Cardiologia, Ciudad Sanitaria Valle Hebron, $\mathbf{P}^{\circ}$ Valle Hebron s/n, Barcelona 35, Spain.

Accepted for publication 22 November 1983
We undertook the present study (a) to determine the incidence and volume of right to left shunts in patients with atrial septal defects by the usual oximetric techniques and direct measurement of the left atrial stepdown and (b) to delineate the factors that may account for a right to left shunt in uncomplicated atrial septal defect.

\section{Patients and methods}

STUDY POPULATION

The haemodynamic data of 40 consecutive patients (18 male and 22 female, age range 8-83 years) with an atrial septal defect seen in our department were reviewed (Table 1). Patients with ostium primum defects or those with other associated cardiac lesions (apart from partial anomalous pulmonary venous drainage) were not included.

\section{CARDIAC CATHETERISATION}

Left and right heart catheterisations were performed percutaneously using the femoral approach. All patients were studied in the fasting state, under mild sedation with either $25 \mathrm{mg}$ intramuscular meperidine or $5 \mathrm{mg}$ diazepam with $25 \mathrm{mg}$ promethazine. Cases 20 
Table 1 Haemodynamic findings in all patients

\begin{tabular}{|c|c|c|c|c|c|c|c|c|c|c|c|c|c|c|}
\hline \multirow{2}{*}{$\begin{array}{l}\text { Case } \\
\text { No }\end{array}$} & \multirow{2}{*}{$\begin{array}{l}\text { Age (yr) } \\
\text { (sex) }\end{array}$} & \multirow[t]{2}{*}{$H R C R$} & \multicolumn{5}{|c|}{ Pressures (mom $\mathrm{Hg}$ ) } & \multicolumn{2}{|c|}{ Oxygen saturation } & \multicolumn{3}{|c|}{ Blood flow (l/min/m $\left.{ }^{2}\right)$} & \multirow{2}{*}{$R p: R s$} & \multirow{2}{*}{$\begin{array}{l}\text { Size } \\
\text { of } A S D \\
\left(\mathrm{~cm}^{2}\right)\end{array}$} \\
\hline & & & $R A$ & $L A$ & $R V E$ & $P A$ & $S A$ & $P V(\%)$ & $S A(\%)$ & $Q p$ & $Q s$ & $\begin{array}{l}L-R \text { sheont } \\
\text { (R-L sherot) }\end{array}$ & & \\
\hline $\begin{array}{l}1 \\
2 \\
3 \\
4 \\
5 \\
6 \\
7 \\
8 \\
9 \star\end{array}$ & $\begin{array}{l}53(\mathrm{~F}) \\
57(\mathrm{M}) \\
43(\mathrm{~F}) \\
28(\mathrm{~F}) \\
37(\mathrm{M}) \\
53(\mathrm{~F}) \\
20(\mathrm{~F}) \\
17(\mathrm{~F}) \\
40(\mathrm{M})\end{array}$ & $\begin{array}{ll}80 & S \\
76 & S \\
84 & S \\
80 & S \\
70 & S \\
90 & S \\
84 & S \\
75 & S \\
70 & S\end{array}$ & $\begin{array}{l}5 \\
6 \\
4 \\
4 \\
1 \\
3 \\
1 \\
4 \\
-1\end{array}$ & $\begin{array}{l}5 \\
5 \\
4 \cdot 5 \\
3 \\
2 \\
3 \\
3 \\
5 \\
2\end{array}$ & $\begin{array}{l}7 \\
9 \\
4 \\
4 \\
2 \\
5 \\
2 \\
4 \\
2\end{array}$ & $\begin{array}{l}24 \\
31 \\
25 \\
16 \\
10 \\
17 \\
10 \\
12 \\
35\end{array}$ & $\begin{array}{l}80 \\
96 \\
88 \\
80 \\
65 \\
70 \\
82 \\
80 \\
95\end{array}$ & $\begin{array}{l}97.5 \\
89.0 \\
96.2 \\
96.0 \\
97.5 \\
92.3 \\
97.0 \\
96.6 \\
94\end{array}$ & $\begin{array}{l}97.5 \\
89.0 \\
95.0 \\
95.5 \\
95.7 \\
92.2 \\
96.5 \\
96.5 \\
90.5\end{array}$ & $\begin{array}{l}5.7 \\
4.5 \\
12.0 \\
6.3 \\
12.8 \\
8.4 \\
6.9 \\
9.3 \\
4.2\end{array}$ & $\begin{array}{l}1.7 \\
2.2 \\
3.1 \\
2.2 \\
5.1 \\
2.2 \\
3.6 \\
3.0 \\
2.7\end{array}$ & $\begin{array}{l}3.8 \\
2.3 \\
9.1 \\
4.1 \\
8.1 \\
6.2 \\
3.3 \\
6.4 \\
1.9\end{array}$ & $\begin{array}{l}0.20 \\
0.14 \\
0.06 \\
0.07 \\
0.05 \\
0.05 \\
0.05 \\
0.03 \\
0.20\end{array}$ & $\geqslant 6$ \\
\hline $10^{*}$ & $72(M)$ & $102 \mathrm{~S}$ & 3 & 7 & 5 & 10 & 83 & $95 \cdot 6$ & 88.4 & 4.8 & $4 \cdot 2$ & & 0.04 & \\
\hline $\begin{array}{l}11 \\
12 \\
13^{\star}\end{array}$ & $\begin{array}{l}27(M) \\
14(M) \\
50(F)\end{array}$ & $\begin{array}{ll}65 & S \\
68 & S \\
70 & S\end{array}$ & $\begin{array}{l}3 \\
7 \\
6.5\end{array}$ & $\begin{array}{l}4 \\
7 \cdot 2 \\
8\end{array}$ & $\begin{array}{l}5 \\
8 \\
7\end{array}$ & $\begin{array}{l}16 \\
16 \\
25\end{array}$ & $\begin{array}{l}96 \\
100 \\
83\end{array}$ & $\begin{array}{l}96.4 \\
95.8 \\
93.4\end{array}$ & $\begin{array}{l}96.5 \\
95.2 \\
88.2\end{array}$ & $\begin{array}{l}12.0 \\
17.5 \\
11.5\end{array}$ & $\begin{array}{l}4 \cdot 7 \\
7 \cdot 2 \\
3 \cdot 4\end{array}$ & $\begin{array}{l}7.1 \\
10.6 \\
8 \cdot 8 \\
(0.71)\end{array}$ & $\begin{array}{l}0.05 \\
0.04 \\
0.12\end{array}$ & $\begin{array}{l}\geqslant 9 \\
\geqslant 9\end{array}$ \\
\hline $\begin{array}{l}14 \\
15 \\
16 \\
17 \\
18 \\
19 \\
20+ \\
21 \\
22 \\
23 \star\end{array}$ & $\begin{array}{l}49(\mathrm{~F}) \\
15(\mathrm{M}) \\
52(\mathrm{~F}) \\
21(\mathrm{~F}) \\
13(\mathrm{M}) \\
13(\mathrm{~F}) \\
9(\mathrm{~F}) \\
59(\mathrm{M}) \\
38(\mathrm{~F}) \\
41(\mathrm{M})\end{array}$ & $\begin{array}{ll}76 & S \\
70 & S \\
65 & S \\
80 & S \\
92 & S \\
78 & S \\
94 & S \\
90 & S \\
100 & F \\
110 S\end{array}$ & $\begin{array}{l}7 \\
5 \\
3 \\
4 \\
4 \cdot 6 \\
4 \\
4 \cdot 6 \\
4 \\
12 \\
5\end{array}$ & $\begin{array}{l}8 \cdot 5 \\
7 \\
3 \\
4 \\
6 \\
4 \\
3 \cdot 2 \\
7 \\
9 \\
5 \cdot 6\end{array}$ & $\begin{array}{l}7 \\
12 \\
10 \\
5 \\
3 \\
5 \\
4 \cdot 5 \\
7 \\
9 \\
8\end{array}$ & $\begin{array}{l}25 \\
20 \\
20 \\
10 \\
17 \\
13 \\
16 \\
26 \\
25 \\
42\end{array}$ & $\begin{array}{l}85 \\
82 \\
106 \\
75 \\
95 \\
76 \\
94 \\
96 \\
80 \\
90\end{array}$ & $\begin{array}{l}92.0 \\
95.9 \\
93.9 \\
96.5 \\
94.5 \\
93.5 \\
95.2 \\
92.6 \\
95.5 \\
93.2\end{array}$ & $\begin{array}{l}92.0 \\
96.0 \\
92.9 \\
94.1 \\
94.5 \\
93.5 \\
95.2 \\
92.1 \\
92.5 \\
84\end{array}$ & $\begin{array}{l}7.6 \\
12.1 \\
6 \cdot 3 \\
4.9 \\
9.4 \\
18.5 \\
14.5 \\
8 \cdot 3 \\
8 \cdot 7 \\
4.4\end{array}$ & $\begin{array}{l}3.5 \\
5.3 \\
2.4 \\
3.1 \\
4.1 \\
4.8 \\
6.9 \\
6.9 \\
2.2 \\
3.1\end{array}$ & $\begin{array}{l}4.11 \\
4.1 \\
6.6 \\
4.0 \\
2.1 \\
5.3 \\
13.7 \\
7.6 \\
1.8 \\
6.7 \\
2.0\end{array}$ & $\begin{array}{l}0.16 \\
0.07 \\
0.06 \\
0.05 \\
0.05 \\
0.03 \\
0.03 \\
0.17 \\
0.09 \\
0.32\end{array}$ & $\begin{array}{l}\geqslant 15 \\
\geqslant 9 \\
\geqslant 9 \\
\geqslant 2\end{array}$ \\
\hline $24^{\star}$ & $68(F)$ & $90 \mathrm{~S}$ & 3 & 4 & 6 & 28 & 80 & 96.5 & 84.5 & 3.0 & $2 \cdot 1$ & & 0.22 & \\
\hline $25^{\star}$ & $39(F)$ & $120 \mathrm{~F}$ & 9 & 10 & 9 & 17 & 80 & 94.7 & 89.4 & 8.0 & $3 \cdot 2$ & & 0.04 & $\geqslant 15$ \\
\hline $\begin{array}{l}26 \\
27 \\
28 \\
29 \\
30 \\
31 \\
32 \\
33 \\
34 \\
35+ \\
36 \\
37 \\
38 \\
39 \\
40\end{array}$ & $\begin{array}{l}24(\mathrm{~F}) \\
16(\mathrm{~F}) \\
83(\mathrm{M}) \\
59(\mathrm{M}) \\
20(\mathrm{M}) \\
13(\mathrm{M}) \\
30(\mathrm{M}) \\
19(\mathrm{~F}) \\
53(\mathrm{~F}) \\
11(\mathrm{M}) \\
26(\mathrm{M}) \\
15(\mathrm{~F}) \\
64(\mathrm{~F}) \\
58(\mathrm{~F}) \\
58(\mathrm{M})\end{array}$ & $\begin{array}{ll}95 & S \\
80 & S \\
62 & S \\
70 & S \\
84 & S \\
92 & S \\
70 & S \\
100 & S \\
86 & S \\
70 & S \\
70 & S \\
78 & S \\
70 & S \\
108 & \mathbf{F} \\
70 & S\end{array}$ & $\begin{array}{l}3 \\
6 \\
5 \\
4 \\
1 \\
2.6 \\
2 \\
3 \\
2 \\
3 \\
6 \\
4 \\
3 \\
16 \\
5.5\end{array}$ & $\begin{array}{l}6 \\
6 \cdot 5 \\
8 \\
5 \\
1 \\
4 \\
1 \\
5 \\
4 \\
5 \cdot 5 \\
7 \\
5 \\
4 \\
18 \\
7\end{array}$ & $\begin{array}{l}2 \\
7 \cdot 5 \\
6 \\
0 \\
2 \\
10.5 \\
7 \\
2 \\
2 \\
4 \\
8 \\
7 \\
10 \\
5 \\
6\end{array}$ & $\begin{array}{l}16 \\
17 \\
25 \\
20 \\
10 \\
13 \\
59 \\
11 \\
12 \\
13 \\
20 \\
18 \\
24 \\
35 \\
45\end{array}$ & $\begin{array}{l}80 \\
75 \\
90 \\
92 \\
85 \\
55 \\
84 \\
95 \\
90 \\
98 \\
71 \\
115 \\
86 \\
95 \\
95\end{array}$ & $\begin{array}{l}97.6 \\
97.7 \\
96.0 \\
98.5 \\
94.9 \\
95.5 \\
94.8 \\
95.6 \\
93.7 \\
93.6 \\
94.5 \\
93.7 \\
90.3 \\
97.2 \\
90.1\end{array}$ & $\begin{array}{l}97.6 \\
95.0 \\
96.0 \\
95.9 \\
94.9 \\
95.6 \\
93.8 \\
94.4 \\
93.7 \\
93.2 \\
94.5 \\
92.6 \\
88.5 \\
96.0 \\
89.2\end{array}$ & $\begin{array}{l}12.0 \\
11.0 \\
5.7 \\
5.7 \\
10.1 \\
21.0 \\
7.1 \\
15.6 \\
10.4 \\
26.6 \\
11.2 \\
11.1 \\
5.5 \\
7.5 \\
5.5\end{array}$ & $\begin{array}{l}3.4 \\
4.0 \\
1.4 \\
3.0 \\
3.2 \\
3.2 \\
3.0 \\
3.3 \\
3.7 \\
4.8 \\
3.8 \\
7.3 \\
2.9 \\
2.2 \\
2.6\end{array}$ & $\begin{array}{l}8.5 \\
7.4 \\
4.3 \\
2.9 \\
6.9 \\
17.8 \\
4.2 \\
12.4 \\
6.7 \\
21.7 \\
7.4 \\
3.8 \\
2.7 \\
5.4 \\
3.0\end{array}$ & $\begin{array}{l}0.05 \\
0.05 \\
0.01 \\
0.10 \\
0.04 \\
0.26 \\
0.28 \\
0.02 \\
0.03 \\
0.01 \\
0.07 \\
0.11 \\
0.10 \\
0.06 \\
0.20\end{array}$ & $\begin{array}{l}\geqslant 6 \\
\geqslant 9 \\
\geqslant 9 \\
\geqslant 6 \\
\geqslant 9 \\
\geqslant 2 \\
\geqslant 6\end{array}$ \\
\hline
\end{tabular}

*Patients with bidirectional shunts (group 1)

tCatheterisation under general anaesthesia. HR, heart rate; $C R$, cardiac rhythm; $S$, sinus rhythm; $F$, atrial fibrillation; $R A$, mean right atrial pressure; LA, mean left atrial pressure; RVED, right ventricular end diastolic pressure; PA, mean pulmonary artery pressure; SA, mean systemic artery pressure; PV(\%), pulmonary vein oxygen saturation; SA $(\%)$, systemic arterial oxygen saturation; Qp, pulmonary blood flow; Qs, systemic blood flow; Rp: Rs, pulmonary to systemic vascular resistance ratio; $L$ R shunt, left to right shunt; $R-L$ shunt, right to left shunt; ASD, atrial septal defect.

and 35 (Table 1) were examined under general anaesthesia.

All patients underwent duplicated sequential oxygen sampling from the pulmonary artery to the vena cava and simultaneously from the systemic artery and the pulmonary veins. Blood oxygen tension was measured by photoreflectance (American Optical Oximeter). Cardiac rhythm, heart rate, left and right atrial pressures, gradient across the defect, and right ventricular, pulmonary, and systemic arterial pressures were determined. The pulmonary and systemic flows and the magnitude of the left to right and right to left shunts were calculated using oximetric methods and the commonly applied formula. ${ }^{11}$ In addition, the ratio of pulmonary to systemic vascular resistance was determined.

\section{SURGERY}

Twenty one cases underwent surgery in this hospital and were found to have ostium secundum defects. The diameter and site of the atrial defect and the coexistence of anomalous pulmonary venous drainage were determined.

CLASSIFICATION OF GROUPS

A sizeable right to left shunt was diagnosed when the 
Table 2 Comparison of data between patients with bidirectional shunts (group 1) and those with left to right shunts only (group 2) (Figures are means $\pm S D$ or *numbers of patients)

\begin{tabular}{|c|c|c|c|}
\hline & $\underset{(n=6)}{\text { Group } 1}$ & $\underset{(n=34)}{\text { Group }} 2$ & $p$ \\
\hline \multirow{3}{*}{ 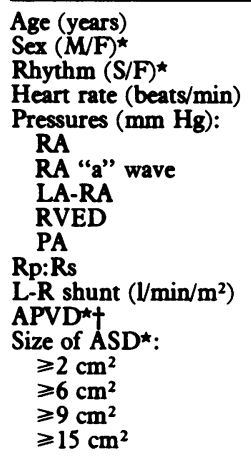 } & $\begin{array}{l}52 \pm 15 \\
3 / 3 \\
5 / 1 \\
94 \pm 21\end{array}$ & $\begin{array}{l}34 \pm 20 \\
15 / 19 \\
32 / 2 \\
80 \pm 11\end{array}$ & $\begin{array}{l}\mathrm{p}<0.01 \\
\text { NS } \\
\text { NS } \\
\text { NS }\end{array}$ \\
\hline & $\begin{array}{l}4 \cdot 2 \pm 3 \cdot 4 \\
8 \cdot 4 \pm 4 \cdot 5 \\
1 \cdot 8 \pm 1 \cdot 3 \\
6 \cdot 1 \pm 2 \cdot 5 \\
26 \cdot 2 \pm 11 \cdot 6 \\
0 \cdot 16 \pm 0.11 \\
3 \cdot 6 \pm 3 \cdot 0 \\
1\end{array}$ & $\begin{array}{l}4 \cdot 5 \pm 3 \cdot 0 \\
6 \cdot 7 \pm 2 \cdot 4 \\
0.9 \pm 1 \cdot 3 \\
5 \cdot 4 \pm 2 \cdot 7 \\
20 \cdot 2 \pm 10.3 \\
0.08 \pm 0.07 \\
6.7 \pm 4 \cdot 4 \\
5\end{array}$ & $\begin{array}{l}\text { NS } \\
\text { NS } \\
\text { NS } \\
\text { NS } \\
\text { NS } \\
\text { NS } \\
\text { p<0.05 } \\
\text { NS }\end{array}$ \\
\hline & $\begin{array}{l}0 \\
1 \\
1 \\
2\end{array}$ & $\begin{array}{l}3 \\
4 \\
9 \\
1\end{array}$ & $\begin{array}{l}\text { NS } \\
\text { NS } \\
\text { NS } \\
\text { NS }\end{array}$ \\
\hline
\end{tabular}

S, sinus rhythm; F, atrial fibrillation; RA, mean right atrial pressure; LA-RA, interatrial gradient; RVED, right ventricular end diastolic pressure; PA, mean pulmonary artery pressure; Rp:Rs, pulmonary to systemic vascular resistance ratio; APVD, anomalous pulmonary venous drainage; ASD, atrial septal defect.

tCase 5 (group 1) and Cases 14, 23, 32, 36, and 38 (group 2).

pulmonary vein to systemic artery oxygen stepdown was $\geqslant 0.7 \mathrm{vol} \%$. Patients were classified into group 1 (left to right and right to left shunts) and group 2 (left to right shunt only).

COMPARATIVE ANALYSIS

The following data were included for comparison between the two groups: age, sex, cardiac rhythm, heart rate, presence of anomalous pulmonary venous drainage, size of the defect at operation, right atrial "a" wave, left to right atrial mean pressure gradient, right ventricular end diastolic pressure, morphology of right ventricular diastolic pressure curve, pulmonary to systemic vascular resistance ratio, and left to right shunt volume. All values were expressed as means $\pm S D$. The $\chi^{2}$ test and the paired Student's $t$ test were used to determine the statistical differences in data between the two groups; a probability (p) value of $<0.05$ was considered to be significant.

\section{Results}

Table 1 gives the individual data for each patient and Table 2 summarises the mean values for both groups. According to our classification, group 1 consisted of six patients and group 234 . The mean right to left shunt in group 1 was $0.67 \pm 0.21 \mathrm{1} / \mathrm{min} / \mathrm{m}^{2}$ (range $0.36-1.0$ ). The arterial oxygen saturation of group 1 ranged from $84 \%$ to $90.5 \%$. Left to right shunt volume was smaller in group $1(\mathrm{p}<0.05$; Figure $a)$.

\section{COMPARATIVE DATA}

There were no significant differences between both groups in mean right atrial pressure, magnitude of the
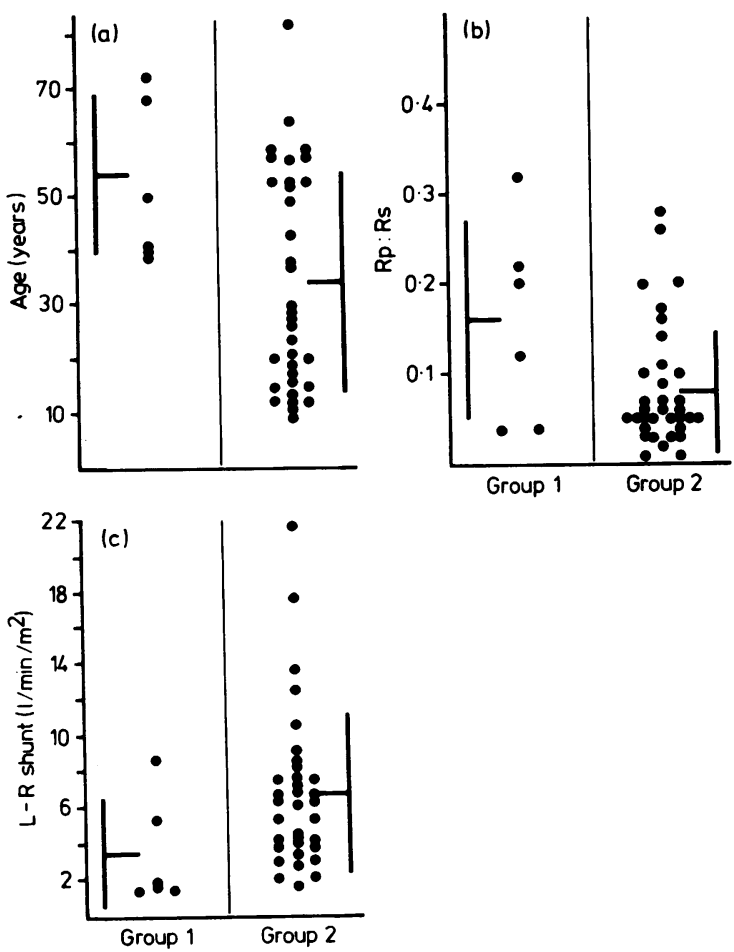

Figure (a) Distribution of ages showing that patients in group 1 (bidirectional shunt) were older than those in group 2 (left to right shunt only) $(p<0.01)$; (b) comparison of pulmonary to systemic vascular resistance (Rp:Rs) ratio (difference $N S$ ); and (c) volume of left to right $(L-R)$ shunt showing that in patients in group 1 the volume was less than that in those in group 2 $(p<0.05)$. Values are means $\pm S D$. 
"a" wave in the right atrium, mean right ventricular end diastolic pressure, left to right atrial gradient, mean pressure in the pulmonary artery, or the pulmonary to systemic vascular resistance ratio (Figure $b$ ). The analysis of the diastolic morphology of the right ventricular pressure curves showed no differences between the groups.

The mean age of patients in group 1 was $52 \pm 15$ years; they were significantly older than those in group 2 ( $p<0.01$; Figure $c)$. There were no statistical differences between both groups in sex, cardiac rhythm (sinus rhythm versus atrial fibrillation), or mean heart rate.

\section{SURGICAL CONFIRMATION AND ANOMALOUS \\ PULMONARY VENOUS DRAINAGE}

In all patients who underwent surgery (four in group 1 and 17 in group 2; Table 1) the diagnosis of an ostium secundum defect was confirmed. The size of the defect was not significantly different between the two groups (Table 2). The prevalence of anomalous pulmonary venous drainage was similar in both groups (NS; Table 2). Systemic venous drainage into the left atrium was excluded in all cases.

\section{Discussion}

Transient right to left shunts occurring in uncomplicated atrial septal defects have been detected with complex techniques using matched catheter systems and biplane cineangiocardiography. ${ }^{1}$ This finding has been confirmed by jugular venous flow velocity curves recorded with a directional ultrasonic Doppler flowmeter ${ }^{2}$ and by cross sectional contrast echocardiography. ${ }^{3}$ Nevertheless, detection of these right to left shunts by peripherally recorded dye dilution curves failed in these patients, suggesting that the amount of shunted blood is small. ${ }^{1}$

A few isolated cases of uncomplicated atrial septal defect with appreciable arterial desaturation and clinical cyanosis have been reported. ${ }^{4-8}$ In such cases no satisfactory explanation for the right to left shunt was found. No previous systematic studies of the left atrial stepdown have been carried out to evaluate the right to left shunt in atrial septal defect. The right to left shunt has, however, been evaluated indirectly by measuring systemic arterial saturation or arterial oxygen content. ${ }^{10}$ Using this last method, Rasmussen et al found that $55 \%$ of patients with uncomplicated atrial septal defect had an abnormally low $\mathrm{PO}_{2}$ compared with a normal control group, ${ }^{10}$ but incomplete oxygenation of blood during pulmonary capillary passage was ruled out in only six of the 28 patients studied.

Our study is probably the first to evaluate the size of the right to left shunt by measuring the pulmonary vein to systemic artery oxygen stepdown; with this method any error caused by pulmonary desaturation due to pulmonary disease, opening of pulmonary arteriovenous shunts, or high flow impairing complete oxygenation of blood during capillary passage is excluded.

In contrast to previous studies, ${ }^{1-8}$ ours suggests that a right to left shunt in these patients may be more important than generally considered, since it may be detected by a routine oximetric technique and does not require a highly sensitive method. We considered that a major right to left shunt was present when the difference between the mean oxygen saturation in the pulmonary veins and the mean saturation in the systemic artery was $\geqslant 0.7 \mathrm{vol} \%$. In our opinion a stepdown of this magnitude exceeds the normal variability in blood oxygen measurements in the left heart chambers, which is less than that seen in the right heart chambers. Thus a sizeable right to left shunt was found in six of the $\mathbf{4 0}$ patients in our study.

In addition to the established causes of cyanosis in atrial septal defect-namely, pulmonary stenosis, tricuspid valve disease, or the superior or inferior vena cava entering the left atrium-the most important condition to be excluded in reversed shunts is pulmonary hypertension. In the present study, however, no significant difference in pulmonary vascular resistance was found between patients with bidirectional and isolated left to right shunts. Some workers have found that slow heart rates enhance right to left shunts, ${ }^{1}$ while others have found abnormally low left ventricular end diastolic pressures, ${ }^{4}$ right atrial hypertension due to tricuspid regurgitation, ${ }^{4}$ or an increase of the " $a$ " wave in the right atrium" as factors that could accentuate the shunt. In this study we matched several variables in patients with and without right to left shunts-namely, "a" wave and right atrial pressure, interatrial gradient, end diastolic right ventricular pressure, and heart rate. In addition, we analysed other variables such as age, sex, cardiac rhythm, size of the defect at surgery, magnitude of the left to right shunt, and coexistence of anomalous pulmonary venous drainage. Table 2 and the Figure show that these variables were similar in both groups, except that the patients in group 1 were older $(52 \pm 13$ versus $34 \pm 20$ years, $p<0.01$ ) and the volume of their left to right shunt smaller than in group $2(3.6 \pm 3.0$ versus $6.7 \pm 4.4 \mathrm{l} / \mathrm{min} / \mathrm{m}^{2}, \mathrm{p}<0.05$ ). We consider that the latter is the consequence rather than the cause of the right to left shunt, because the size of the defect and the number of patients with anomalous pulmonary venous drainage were similar in both groups.

It is interesting that the presence of right to left shunts is age related, since it raises the possibility that reversed shunting may be a feature of the natural history of atrial septal defect. Our finding is consistent 
with that of Levin et al, who studied children between the ages of 3 and 14 years and did not find any right to left shunts detectable by dye dilution curves; ${ }^{1}$ it is also consistent with that of Gault $e t$ al, who studied atrial septal defect in patients over the age of 40 years and found a considerable number with systemic arterial oxygen desaturation that could not be ascribed to pulmonary artery hypertension associated with right to left shunts. ${ }^{12}$

Our results could possibly be explained by a congenital anomalous systemic venous connection resulting in the return of desaturated blood to the left atrium, directly or by means of a preferential shunt from the inferior vena cava. ${ }^{56}$ This theory would not, however, explain the increased prevalence of right to left shunts in older patients. Attention must, therefore, be given to those factors that result from long standing right heart volume overload-namely, increased pulmonary arterial pressure or reduced distensibility of the right ventricle. The first factor was not found to be important in our study. It is a common belief that the relative distensibilities of the two ventricles are the chief determinants of the size and direction of the shunt, ${ }^{9}$ while a minimal or no gradient is generally found between the two atria. Several workers ${ }^{4}{ }^{7}$ have speculated that change in right ventricular relaxation may be the cause of reversed shunting, but only Ciafone et al found one patient with anomalies of the right ventricular pressure curve (an early diastolic dip followed by a plateau and a prominent "a" wave). ${ }^{7}$ Neither in the three cases investigated by Somerville 4 nor in ours were these anomalies found. Thus, a more precise study of right ventricular diastolic properties is needed to clarify their role in the natural history of the right to left shunt.

Our study, therefore, indicates that right to left shunts in uncomplicated atrial septal defect may be detected easily by the usual oximetric technique in an appreciable number of patients. The patients with right to left shunts were significantly older. Factors other than pulmonary hypertension, related to long standing volume overload of the right heart, should be investigated.

\section{References}

1 Levin AR, Spach MS, Boineau JP, Canent RV Jr, Capp MP, Jewett PH. Atrial pressure-flow dynamics in atrial septal defect (secundum type) Circulation 1968; 37: 476-88.

2 Kalmanson D, Veyrat C, Derai C, Savier CH, Berkman $M$, Chiche $P$. Non-invasive technique for diagnosing atrial septal defect and assessing shunt volume using directional Doppler ultrasound. Correlations with phasic flow velocity patterns of the shunt. Br Heart f 1972; 34: 981-91.

3 Serruys PW, van den Brand M, Hugenholtz PG, Roelandt J. Intracardiac right to left shunts demonstrated by two-dimensional echocardiography after peripheral vein injection. Br Heart f 1979; 42: 429-37.

4 Somerville W. Atrial septal defect: reversed shunt with normal pulmonary vascular resistance. $\mathrm{Br}$ Heart $\mathcal{F} 1958$; 20: 265-6.

5 Winters WL Jr, Cortes F, McDonough M, et al. Venoarterial shunting from inferior vena cava to left atrium in atrial septal defects with normal right heart pressures. Report of two cases. Am $\mathcal{F}$ Cardiol 1967; 19: 293-300.

6 Maillis MS, Cheng TO, Meyer JF, Crawley IS, Lindsay $\mathrm{J} \mathrm{Jr}$. Cyanosis in patients with atrial septal defect due to systemic venous drainage into the left atrium. $A m \mathcal{F}$ Cardiol 1974; 33: 674-8.

7 Ciafone RA, Aroesty JM, Weintraub RM, LaRaia PJ, Paulin S. Cyanosis in uncomplicated atrial septal defect with normal right cardiac and pulmonary arterial pressures. Chest 1978; 74: 596-9.

8 Swan HJC, Burchell HB, Wood EH. The presence of venoarterial shunts in patients with interatrial communications. Circulation 1954; 10: 705-13.

9 Dexter L. Atrial septal defect. Br Heart $\mathcal{f}$ 1956; 18: $209-25$.

10 Rasmussen K, Simonsen S, Storstein O. Quantitative aspects of right-to-left shunting in uncomplicated atrial septal defects. Br Heart $\mathcal{F}$ 1973; 35: 894-7.

11 Grossman W. Cardiac catheterization and angiography. 2nd ed. Philadelphia: Lea and Febiger, 1980: 136.

12 Gault JH, Morrow AG, Gay WA Jr, Ross J Jr. Atrial septal defect in patients over the age of forty years. Circulation 1961; 37: 261-72. 